\title{
Medical Schools in National Capital Territory-A Historical and Functional Perspective
}

\author{
Shridhar Dwivedi ${ }^{1}$ Amitesh Aggarwal ${ }^{2}$ \\ 1 Department of Cardiology, National Heart Institute, New Delhi, India \\ ${ }^{2}$ Department of Medicine, University College of Medical Sciences \& \\ GTB Hospital, Delhi, India
}

Address for correspondence Shridhar Dwivedi, MD, PhD, FAMS, FRCP, FIACS, FISAR, FICP, National Heart Institute, New Delhi 110065, India (e-mail: shridhar.dwivedi@gmail.com).

\author{
Abstract \\ Keywords \\ - medical schools \\ - National Capital \\ Territory \\ - Lady Hardinge \\ Medical College \\ - All India Institute of \\ Medical Sciences \\ - Maulana Azad \\ Medical College \\ - University College of \\ Medical Sciences
}

Establishment of a medical school is predominantly a political decision. Its basic aim is to further the cause of medical education. Inbuilt within this objective is looking after sick people, bringing improvement in their health, and indirectly improving their understanding of health. Delhi, being the capital city of the country, is governed by the state as well central authorities, thereby enjoying dual benefits. Currently, it has some 10 medical schools/institutes with the objectives of providing quality medical education, research and health to its people. Notably, each one has its own historical legacy and distinctive character, as evident in their respective names, logo, motto and mission statement. This article briefly discusses the historical, socioeconomic, geopolitical, and distinctive characters of each of these institutions.

\section{Preamble}

It is said that only a healthy man is capable of fulfilling all the four coveted aims of human life that is, perform religious duties, earn some money, procreate, and attain final salvation. Then, the obvious question is who shall reveal the principles of sound health and who would provide relief in case someone falls of sick. The most plausible answer is any person who has the sound understanding and skill of human anatomy, its functioning, knowledge about the disease process, its amelioration, and prevention of these maladies. In India, such persons till the early 19th century were known as "Vaidyas" or "Hakeems" who used to practice "Ayurveda/ Hikmat." Their training used to be held at Sanskrit Colleges/Pathshalas/Gurukuls/Madarsas under the mentor- ship of renowned Vaidyas/Hakeems, respectively. Although strong in clinical teaching, they lacked structured formal teaching of anatomy, physiology, pathology, or laboratory investigations. It almost took 65 years for colonial British rulers to convince them to start medical schools structured on the European model, primarily British-based teaching for training of native Indians who could serve the needs of East India Company employees. The first such school was initiated in 1822 at Kolkata in the old Sanskrit Pathshala, which used to be home of Sanskrit teaching as well as teachings of Ayurveda. It was finally rechristened as Calcutta Medical School. The reason why Kolkata was chosen first was because the British started their political journey from Plassey (June 1757) and thereafter formed the Bengal Presidency
DOI https://doi.org/ 10.1055/s-0041-1736505. ISSN 0379-038X. (c) 2022. National Academy of Medical Sciences (India). All rights reserved.

This is an open access article published by Thieme under the terms of the Creative Commons Attribution-NonDerivative-NonCommercial-License, permitting copying and reproduction so long as the original work is given appropriate credit. Contents may not be used for commercial purposes, or adapted, remixed, transformed or built upon. (https://creativecommons.org/ licenses/by-nc-nd/4.0/)

Thieme Medical and Scientific Publishers Pvt. Ltd., A-12, 2nd Floor, Sector 2, Noida-201301 UP, India 
and made Kolkata their first Indian capital. Interestingly, one finds this pattern of establishing a medical school based on political considerations vis-a-vis socioeconomic reasons or geographical considerations. ${ }^{1}$ After Kolkata, there were at least seven more medical schools which came up across the length and breadth of India, namely, Madras Medical College (almost the same time as that of Calcutta Medical School in 1835), Grant Medical College (1845), Agra Medical School (1854), which was later on upgraded as a full-fledged medical college named SN Medical College, KEM Lahore (1860), Prince of Wales Medical College and Hospital, Patna (1874), CMC Vellore (1900), and King George Medical College, Lucknow (1911). Interestingly, King George V had declared New Delhi to be the future capital of British India on December 12, 1911.

\section{Lady Hardinge Medical College and SSK Hospital}

It is credited to be the Delhi's first medical college built during the British regime in 1916, soon after the Indian capital had moved from Kolkata to New Delhi in $1911 .^{2}$ The wife of then Vice Roy and Governor General of India, Lord Hardinge, took a keen interest in the welfare of women. Her enthusiasm for women empowerment led her to conceive a medical college exclusively for women in the new capital, because Indian girls were very reluctant to join coed medical schools existing at Kolkata, Chennai, Lahore, Mumbai, Lucknow, Patna, and Agra. Lord Hardinge jumped on this idea and accepted the proposal. Interestingly, Lord Hardinge himself was intensely interested in furthering education in India. He was also instrumental in the establishment of Banaras Hindu University in 1916. The foundation stone was laid by Lady Hardinge on March 17, 1914, and the college was named Queen Mary College \& Hospital to commemorate the visit of Queen Mary between 1911 and 1912. LHMC started in 1916. Unfortunately, Lady Hardinge, who played pivotal role in starting LHMC, died before the college came formally into existence; therefore, it was decided to name the new college as LHMC in the memory of Lady Hardinge. Its motto in its logo is in Latin, "Per Ardua Adastra," which means through adversity to stars (-Fig. 1). It is a sheer coincidence that this is also the motto of the Royal Air Force of United Kingdom. The first principal was Dr. Kate Platt and the college admitted 16 students. As the college was then affiliated to the University of the Punjab, the students had to attend their final examinations at King Edward Medical College in Lahore. The college became affiliated to the University of Delhi in 1950, and postgraduate courses were started in 1954. LHMC has undergone a sea change in its 100 plus year's journey. Its doors have now been made open for boys for postgraduate studies. Brand LHMC still holds its old charisma for girl students who cherish to be called "Hardonians" as a matter of pride. This is one of the three medical colleges in Delhi which are affiliated to the University of Delhi. The other two are Maulana Azad Medical College and University College of

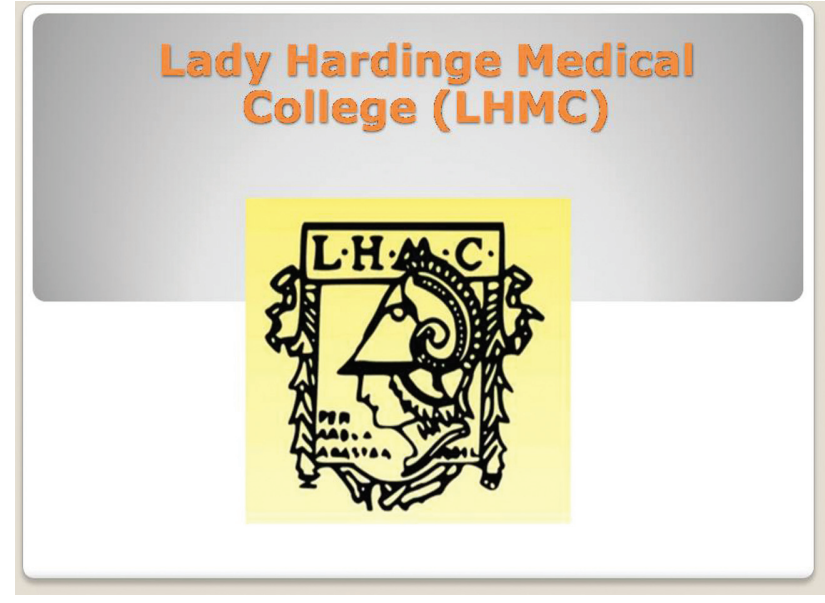

Fig. 1 Logo of Lady Hardinge Medical College.

Medical Sciences. LHMC is directly under the administrative control of the central government.

The old building, which has been declared as a heritage building, possessed rich flora and greenery. Big trees of Terminalia arjuna stand lined up on either side of its main road inside the campus. It is a matter of curiosity that why no one got interested in assessing the role of Terminalia arjuna in cardiovascular diseases. These big trees have given way to renovation and expansion of infrastructure. The associated hospitals have been named after a renowned woman politician, Shrimati Sucheta Kriplani, former UP chief minister and wife of Acharya Kriplani. It is now home to all types of sick patients, male or female. Another well-known hospital attached to LHMC is Kalawati Saran Children Hospital, meant for children and which attracts patients from all over the country. The first antiretroviral therapy (ART) center for children in the country was also started in LHMC in 2007.

Some of the illustrious alumni and professors of LHMC have brought laurels to their alma mater. Notable among them are Dr. Sushila Nayyar, who later on became the health minister of India and Dr. S Padmavati who joined LHMC as lecturer in medicine in 1952 and set up the first cardiology clinic and "cath laboratory" in north India in 1954. The present generation of young faculty charged with enthusiasm and technology are striving hard to restore its past glory much beyond "Per ArduaAdastra" in accordance with the LHMC motto.

\section{All India Institute of Medical Sciences}

As soon as India got its independence in 1947, its first prime minister Pandit Jawahar Lal Nehru started building a chain of scientific and industrial institutions of excellence. He always dreamt to have an excellent center for medicine, which should not only be world class but also be able to show path to other medical institutions in the country. With this in view, he and his first health minister Ms. Raj Kumari Amrit Kaur founded the All India Institute of Medical Sciences (AIIMS) in 1956. The initial proposal to set up the institute at Calcutta was turned down by the then chief minister of West Bengal, Bidhan Chandra Roy. Much credit for building 


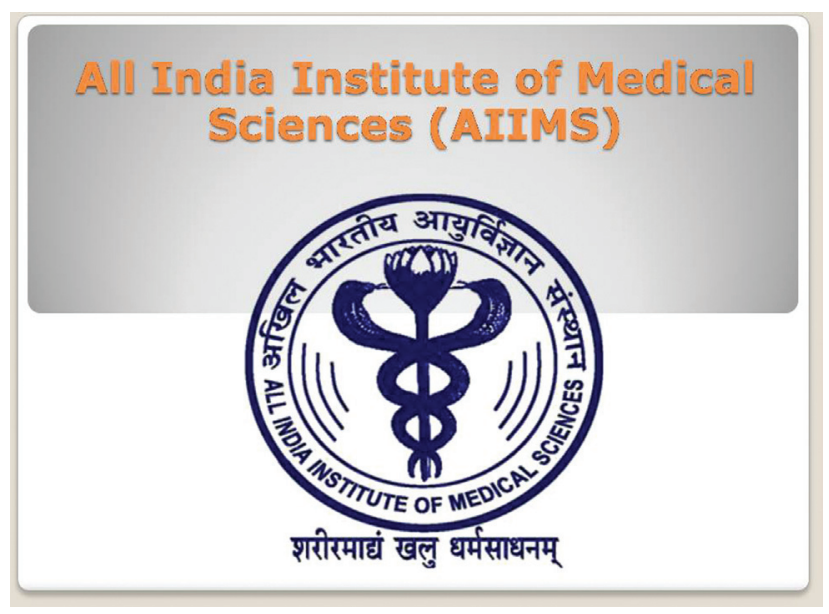

Fig. 2 Logo of All India Institute of Medical Sciences.

this premier institution goes to Ms. Raj Kumari Amrit Kaur who organized funds from the United Kingdom, Germany, Austria, and other countries. It was thus seen that after almost a lapse of 50 odd years that the capital city of Delhi got its second medical college but at the same time second to none in the country, enjoying the formidable reputation of one of the finest in the world. Its motto has been taken from the Upanishad, which means that "the body is indeed the primary instrument of dharma" (-Fig. 2).

It is an autonomous institute enjoying the status of a deemed university. Interestingly, it started its early days in the barrack of its neighbor, Safdarjung Hospital. Pandit Nehru took great personal pains to bring a faculty from abroad and across India. The founder director Prof. BB Dikshit, Prof. Sujoy B Roy, Prof. KN Wig and Prof. V Ramalingaswami (who later on became Director General of Indian Council of Medical Research [ICMR]), to name a few, were stalwarts in their field who nurtured this institute in its formative years. That legacy still continues. It imparts undergraduate, postgraduate, and superspecialty training in all disciplines of medicine. It has now been entrusted to mentor another dozen upcoming AIIMS all over the country. Its alumni, the proud "AIIMSonians," are like galaxies of the medical word spread all over India as well as across the globe. Some of its pioneering alumni are as follows: P Venugopal, who performed the first successful heart transplant in the country and pioneered it later on, K Srinath Reddy (President, Public Health Foundation of India), Jagat Narula (Editor-in-Chief of the Journal of American College of Cardiology: Cardiovascular Imaging), Deepak Chopra (Indian-born American author and a public speaker), Arvinder Singh Soni (pioneer in the field of liver transplantation), and RC Deka (one of the pioneers of cochlear implant surgery in India and who performed the country's first bilateral cochlear implantation surgery), to name a few.

\section{Maulana Azad Medical College}

Maulana Azad Medical College is one of the most prestigious and most sought after medical schools after the iconic AIIMS (Delhi). It was conceived way back in 1936 by Lt. Col. Martin Cruickshank, medical superintendent of Irwin Hospital,

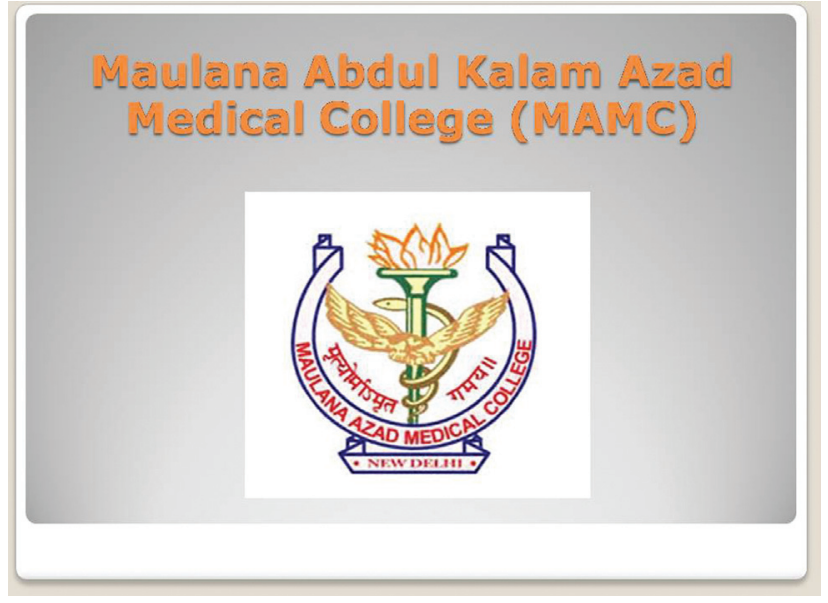

Fig. 3 Logo of Maulana Azad Medical College.

which is currently known as Loknayak Jai Prakash Narayan Hospital (LNJP). ${ }^{3,4}$ Another attempt was made in 1957 when a composite medical college was established attached with the Irwin Hospital. Finally, in 1958, a medical college by the name of Delhi Medical College was established at the behest of then Delhi leaders and the tacit support of Pandit Gobind Ballabh Pant, who persuaded Pandit Jawahar Lal Nehru to lay its foundation stone at a site which used to house the old central jail of Delhi. Interestingly, it was a historic place where great martyr Master Amir Chand and his other friends were hanged for the Hardinge bomb case. The site has been declared as heritage site. The Delhi Medical College was soon renamed as Maulana Azad Medical College (MAMC) in memory of India's first education minister who himself was a great reformist. Its motto which is inscribed in its logo is which means from mortality to immortality (-Fig.3). In the medical college context, it may have meant from sickness to health. It has been taken from Brihadaranyaka Upanishad. The full verse runs in the following manner: Major General BL Taneja, a renowned pathologist, was its founder principal. He laid a strong academic and research foundation for this college. The first batch consisted of some 60 students. The main associated hospital continued to be Irwin Hospital, which presently has grown as a colossus of three distinct hospitals-main building housing LNJP Hospital (nee Irwin Hospital), superspecialty GB Pant Hospital (1961, now called GB Pant postgraduate institute of medical education and research [PGIMER]), and Guru Nanak Eye Center. ${ }^{5}$ They have some 2400 beds among them. MAMC is currently under the administrative control of government of Delhi. It is affiliated to the University of Delhi, a distinction which is also shared by University College of Medical Sciences (UCMS) and LHMC. It is to the credit of this great institution that it has maintained its place within the top 6 medical institutions of the country. "Maulanians" always take pride in some of their distinguished alumni such as YP Munjal, the erstwhile API president, SNA Rizvi, former HOD medicine MAMC, OP Yadava, CEO and chief of CTVS, National Heart Institute, Jagdish Kaur, regional adviser, TFI, WHO regional office for South East Asia, Upendra Kaul, interventional cardiologist and the winner of Dr. BC Roy Award and Padma Shri, 
and so many other illustrious academicians holding chairs in almost all Delhi medical institutes in its 60-year plus journey.

\section{University College of Medical Sciences}

Established in 1971, UCMS has a checkered history. It had its birth pangs at the astrophysics tower in the chemistry block, Department of Chemistry, University of Delhi. ${ }^{6}$ The students had their clinical postings for practicals at the Safdarjung Hospital for 125 students. An additional 50 students were sent to Lala Lajpat Rai Memorial Medical College at Meerut in Uttar Pradesh. Subsequently, it got shifted to Safdarjung Hospital, where it stayed almost for a decade and then moved finally to its present abode at GTB Hospital, Dilshad Garden, in 1986. It enjoys the distinction of being the only constituent medical college of the University of Delhi. Prof. AS Paintal, the renowned medical scientist, was its first principal. Notably, the logo of UCMS was designed by Prof. Satendra Sharma, who was student of this college at that time. The motto of UCMS is which means "O mother lead me to brightness from darkness" (-Fig. 4). UCMS took rapid strides in academics after coming to the GTB campus, because it now had its own academic and clinical faculty plus the GTB hospital staff. It has made its mark in the entire country as a center of excellence with accredited national ranking among the top 10 medical schools of the country. Besides regular undergraduate training, it offers postgraduate teaching programs in all major disciplines of medicine. Efforts are afoot to start superspecialty training programs in endocrinology, nephrology, and urology in the near future. This is the only medical institution in the entire capital city which has its own college anthem "UCMS Kulgeet" composed by Prof. Shridhar Dwivedi. ${ }^{7}$ Its alumni are spread all over the world and in all major medical institutions of the capital city, occupying chairs in their chosen disciplines. Notable among them are Palash Sen, an Indian singer and founder of India's rock band Euphoria, Mahesh Sharma, an Indian politician from Bharatiya Janata Party, Padmashri Sujoy K Guha, an Indian biomedical scientist and inventor of RISUG, the first reversible male contraceptive, Ashish Suri, an Indian neurosurgeon and one of the group of surgeons who performed the first 3D brain

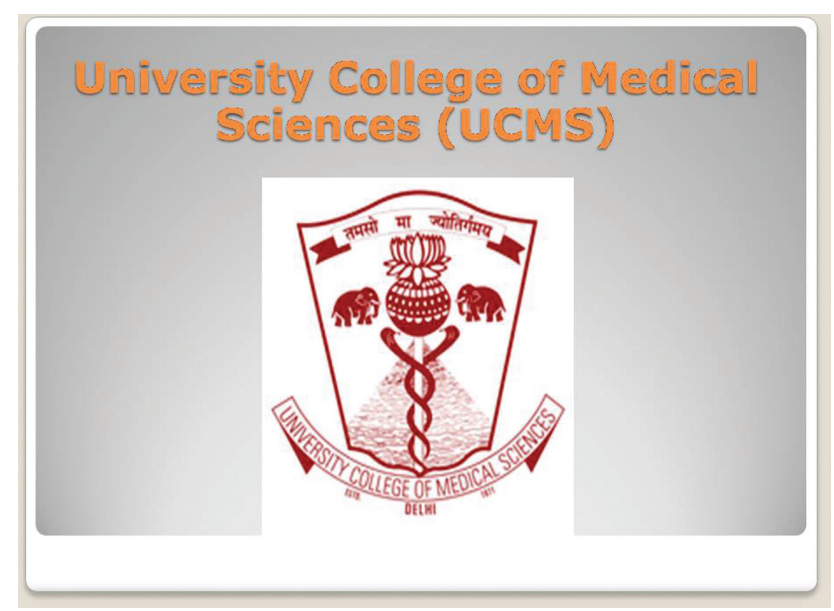

Fig. 4 Logo of University College of Medical Sciences. surgery and the first surgery to implant a spinal cord stimulator in India, Sanjay Tyagi, former dean of MAMC and DG DGHS, Ashok Saxena, former DG DGHS, Sandeep Mahajan, nephrologist at AIIMS, Jagriti Bhatia, pharmacologist at AIIMS, Anupam Prakash, Editor of Indian Journal of Medical Specialties, Dheeraj Shah, Editor of Indian Pediatrics, Hitendra Jain, a top notch professional in cardiac imaging, United States, and Girish Dwivedi, renowned cardiologist at University of Western Australia, to name a few.

\section{Vardhman Mahavir Medical College}

Soon after UCMS moved to its present location at Dilshad Garden in 1986, the ministry of health and family welfare, government of India, decided to open another medical college attached to the Safdarjung Hospital. The idea was to meet the rising needs of medical doctors and optimally utilize the immense human and clinical resources available at this mammoth complex. Thus, Vardhman Mahavir Medical College (VMMC) was born in $2002 .^{8}$ The inauguration of the college was done by the then honorable prime minister Sh. Atal Bihari Vajpayee on December 17, 2001, in the presence of Dr. CP Thakur and founder principal Dr. Jagdish Prasad. Interestingly, its motto is inscribed in English-"In the service of humanity," definitely a utopian wish (-Fig. 5). It has one of the Asia's largest teaching hospital, the Safdarjung Hospital, owing its origin from the British period. During the Second World War, some barracks were rapidly constructed near Safdarjung's tomb to establish a medical center for American troops fighting in this region. After the Second World War was over, America handed over the hospital to the Indian government, now known as the Safdarjung Hospital. It is directly under the control of ministry of health and family welfare. It can boast itself to be a proud nucleus of three medical colleges of the capital city. It was in 1956 that the initial two batches of India's premier institute, AIIMS, got their education and training in its barracks. Later on, it was home to UCMS, which again got shifted to GTB Hospital at a later point in time. Ultimately, it now has its own VMMC. It is affiliated to the Guru Gobind Singh Indraprastha University.

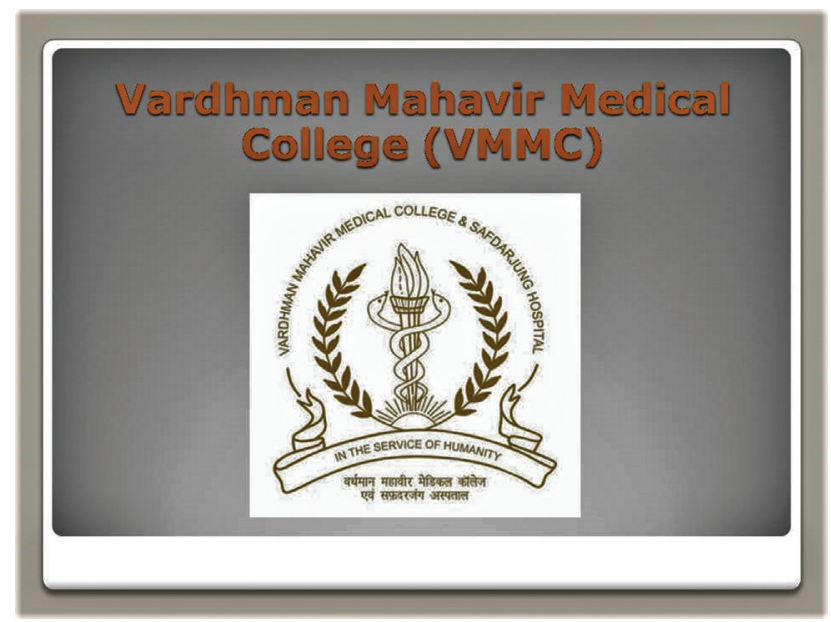

Fig. 5 Logo of Vardhman Mahavir Medical College. 


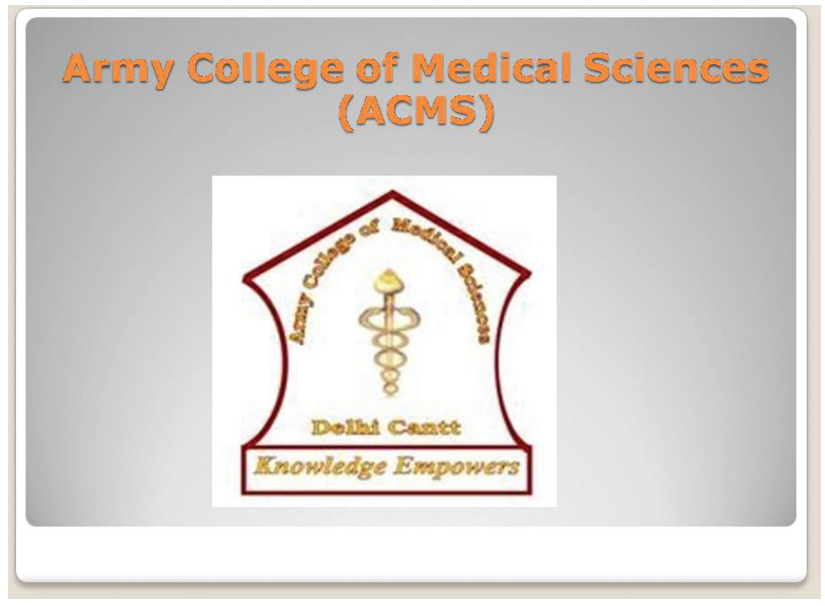

Fig. 6 Logo of Army College of Medical Sciences.

\section{Army College of Medical Sciences}

Army College of Medical Sciences (ACMS) is supported by the Army Welfare Education Society (AWES) of the Indian Army for wards of serving and retired personnel of the Indian Army. ${ }^{9}$ It is situated near the base hospital Delhi cantonment, New Delhi. The annual intake of students in this college is 100. It is an army-aided college run by the Indian Army and is among the top 25 medical colleges in India. The college was opened in 2008 for its first batch of MBBS students. Its motto is "Knowledge empowers" (-Fig. 6), which signifies that knowledge is the basis of progression. It is affiliated to the Guru Gobind Singh Indraprastha University.

\section{Hamdard Institute of Medical Sciences and Research}

The visionary founder of Jamia Hamdard (Hamdard University), Janab Hakeem Abdul Hameed, had dreamt of having a medical college besides the already existing Unani school in the university campus a long time ago in 1990. His worthy successor, Janab Abdul Mueed, took it upon himself to make his dream come true in the form of Hamdard Institute of Medical Sciences and Research (HIMSR). ${ }^{10}$ The entire process was accelerated with the joining of Dr. GN Qazi as vice chancellor of Jamia Hamdard who brought Prof. S Dwivedi as the founder principal in 2011. The Medical Council of India (MCI) gave its permission to start MBBS courses on June 20, 2012, from the 2012-13 academic session. The first batch of 100 MBBS students was admitted based on a competitive test held by the university. Some seats are reserved for minority community based on merit. Notably, this is the first and only public-private partnership model of a medical institute in the entire capital city of Delhi. It is supported by a 650-bedded Hakeem Abdul Hameed Centenary hospital in addition to its refurbished Majeedia Hospital, etched in the memory of the neighborhood since 1984. HIMSR now has postgraduate courses in most pre, para, and clinical subjects. HIMSR has carved out a niche for itself in the academic circle of the medical fraternity not only in Delhi but also in the entire country, because of its dedicated faculty, which is mix of

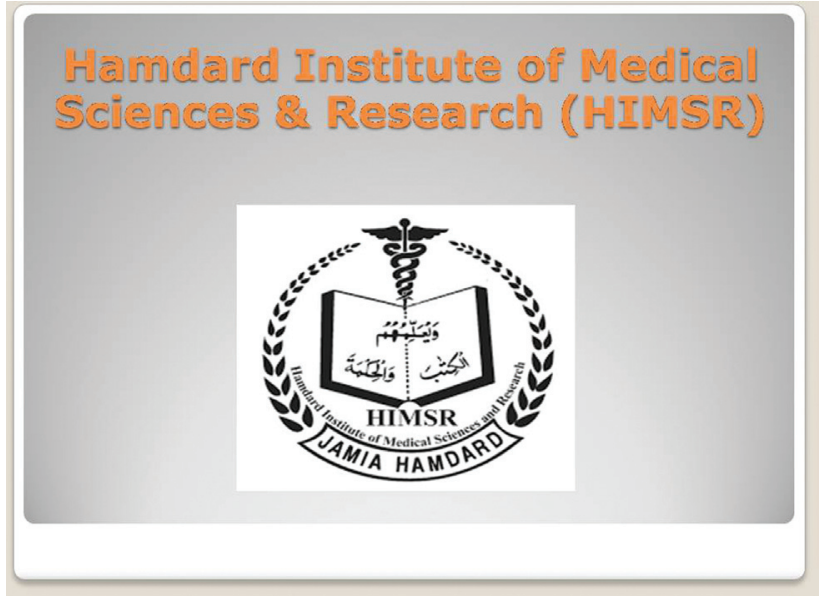

Fig. 7 Logo of Hamdard Institute of Medical Sciences and Research.

wisdom combined with youth. In the short span of its existence, it has been ranked to be the seventh best in national ranking among privately managed medical schools. Its founder faculty started several innovative programs like school health lectures, early exposure to clinical teachings/integrated teachings, observing all World Health Days, which made its presence felt in all capital institutions. The motto inscribed in its logo is written in Arabic which

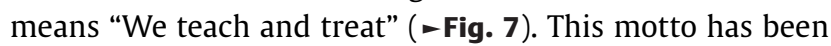
further expanded as follows: "Where the eyes share your grief, Ears eager to hear all your calls, Hands meant always to render relief, Heart filled up with passion and mind guided by science, Welcome to HIMSR and Centenary Hospital." HIMSR is constituent college of Jamia Hamdard.

\section{North Delhi Municipal Corporation Medical College}

In pursuit to extend its welfare wing, the North Delhi Municipal Corporation (NDMC) decided to establish its own medical school under its ambit in the north Delhi area in 2013 and named it as North Delhi Municipal Corporation Medical College. ${ }^{11}$ Another compelling reason was to make full use of its human resources at Hindu Rao Hospital, which was in existence since 1911. NDMC has also learnt long way from its sister organization at Mumbai, which had developed the skill and expertise of running medical schools in their respective zones. The project was conceived by Mr. PK Gupta, Commissioner and Mr. Mayank Sharma, Additional Commissioner (H) NDMC. The motto of NDMC Medical College is same as that of UCMS (-Fig. 8). The philosophy of imparting education carries this inseparable message in several institutions. Its first dean/principal was Prof. Rani Kumar, former Dean, AIIMS. It has been allowed to admit 50 undergraduate students for the time being and is affiliated to the Guru Gobind Singh Indraprastha University. 


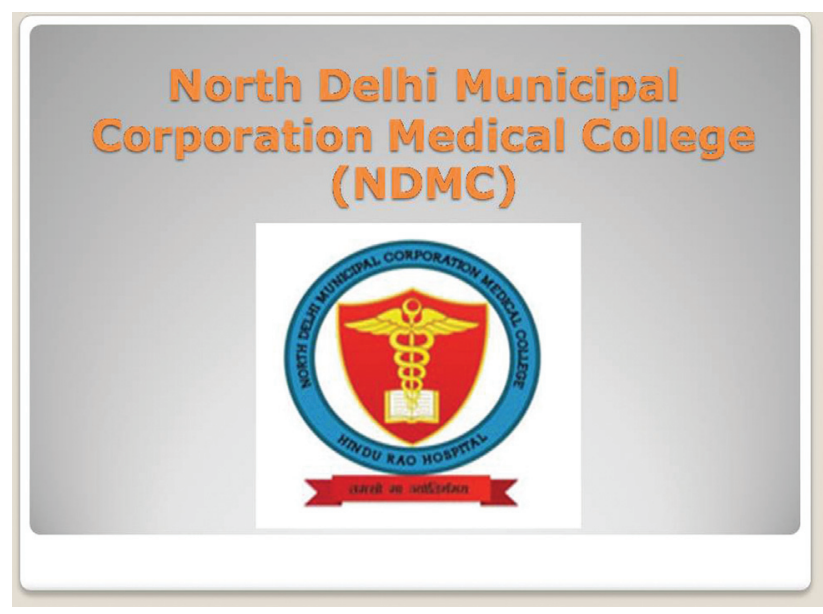

Fig. 8 Logo of North Delhi Municipal Corporation Medical College.

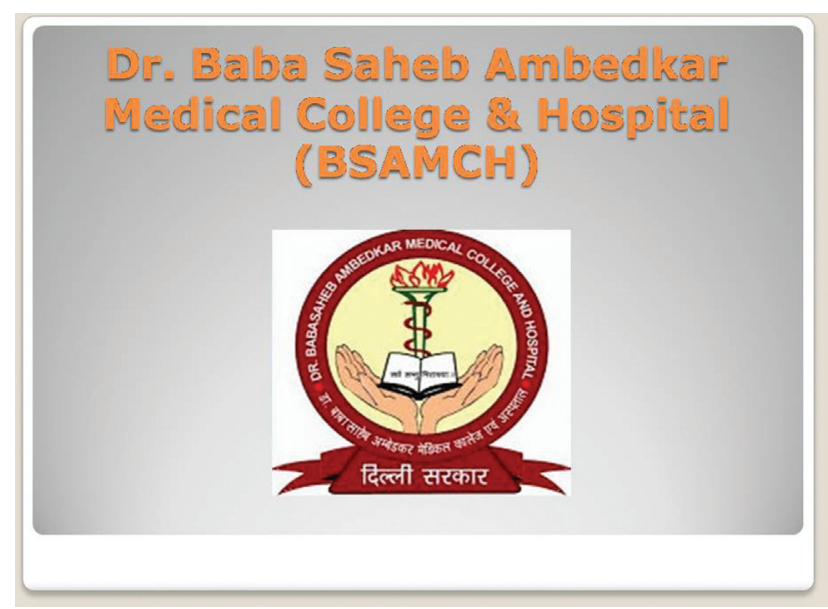

Fig. 9 Logo of Dr. Baba Sahib Ambedkar Medical College and Hospital.

\section{Dr. Baba Saheb Ambedkar Medical College and Hospital}

The west Delhi district of the capital city was without any medical institution worth its name since Independence. Named after leading activist, social reformer, first law minister of free India, and chief architect of the Constitution of India, Dr. Baba Saheb Ambedkar, this medical college was established by the government of national capital territory (NCT) of Delhi in 2016. ${ }^{12}$ The 540-bedded Dr. Baba Saheb Ambedkar College and Hospital (BSAMCH) is located, in 29.4acre campus. Its logo is which means be a light for yourself (-Fig. 9). Its first batch of 98 students started their medical career in2016. It is also affiliated to the Guru Gobind Singh Indraprastha University.

\section{Atal Bihari Vajpayee Institute of Medical Sciences}

To meet the increasing requirement of trained medical doctors in the country, make full use of existing resources at postgraduate institute of medical education and research-

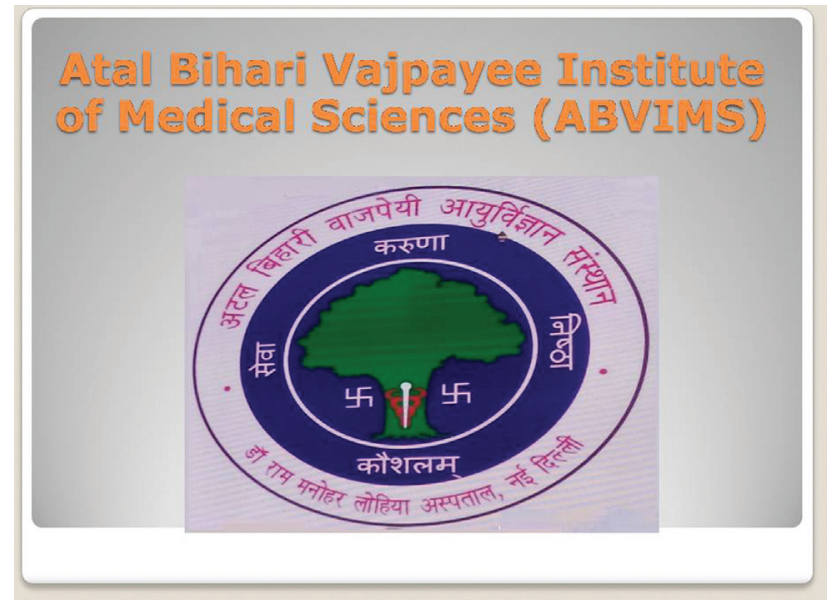

Fig. 10 Logo of Atal Behari Vajpayee Institute of Medical Sciences.

Ram Manohar Lohia (PGIMER-RML) Hospital, and commemorate the memory of late Prime Minister Shri Atal Bihari Vajpayee, the union government decided to open the 10th medical school in NCT known as Atal Bihari Vajpayee Institute of Medical Sciences (ABVIMS). ${ }^{13}$ This college is located in the premises of RML Hospital, New Delhi. It was formally inaugurated on August 15, 2019, by Dr. Harsh Vardhan, the union health minister. It is worthwhile to mention that Dr. Ram Manohar Lohia hospital's previous name was Willingdon Hospital, established by the British for their staff. It had only 54 beds to start with. After independence, its control was shifted to the New Delhi municipal committee. In 1954, its control was again transferred to the government of India. Besides regular undergraduate program, the college has been running postgraduate programs in all branches of medicine. Its motto has been mentioned as " which implies service, compassion, dedication and skill (-Fig. 10). ABVIMS is also affiliated to the Guru Gobind Singh Indraprastha University.

Conflict of Interest

None declared.

\section{References}

1 Dwivedi S. Dissertation for Post Graduate Diploma in Health Planning and Administration [dissertation]. University of Leeds, United Kingdom: Nuffield Institute of Health Sciences; 1984

2 "History of Lady Hardinge Medical College". Lady Hardinge Medical College Alumni Association. Accessed from the original on 16 March 2017

3 Singh D. Maulana Azad Medical College \& Associated Hospitals -Legacy and Heritage -Coffee table Book. New Delhi: G B Pant Hospital; 2008

4 Cooper N. The world's best hospitals 2020. Newsweek. May 2, 2020

5 Singh D, Agarwal A, Sakhuja P, et al, eds. Gobind Ballabh Pant Hospital - Coffee Table Book. New Delhi: GB Pant Hospital; 2014

6 Dwivedi S. UCMS: The cradle of healing, learning and research in health sciences India. Med Times 2017

7 Accessed September 8, 2020 at: https://www.facebook.com/ UCMS.Delhi/posts/kulgeet-by-dr-s-dwivedi-hod-medicine-ucmshttpwwwyoutubecomwatchv_eqzanteqa8/139491836080461/

8 "About Medical College \& Safdarjung Hospital". Accessed from the original on 25 March 2008. Retrieved 2 July 2008 
9 "List of Colleges Teaching MBBS". Medical Council of India. Accessed from the original on 18 March 2013. Retrieved 29 December 2011.

10 Patwari AK. Hamdard Institute of Medical Sciences and Research. Hamdardians 2015;2:38

11 Accessed August 29, 2020 at: http://www.northmcd.com/ medicalcollege/
12 Accessed August 29, 2020 at: http://bsamch.ac.in/

13 "Post-graduate institute at RML becomes a reality - Hindustan Times.". Accessed August 29, 2020 at: https://www.hindustantimes.com/delhi/post-graduate-institute-at-rml-becomes-a-reality/story-OKNTZpMLzpyLRIHMfEAdEL.html 